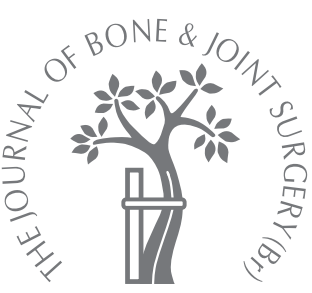

G. C. Babis, V. I. Sakellariou, M. I. O’Connor, A. D. Hanssen, F. H. Sim

From the Mayo Clinic, Rochester, Minnesota

\title{
Proximal femoral allograft-prosthesis composites in revision hip replacement
}

\author{
A 12-YEAR FOLLOW-UP STUDY
}

G. C. Babis, MD, PhD, Associate Professor in Orthopaedics V. I. Sakellariou, MD, Resident in Orthopaedics First Department of Orthopaedics University of Athens, Attikon University General Hospital, Rimini Street, Chaidari, Attica, Greece 12462.

M. I. O'Connor, MD, Associate Professor of Orthopaedics Department of Othopaedic Surgery

Mayo Clinic, 4500 San Pablo Road, Jacksonville, Florida 32224, USA

A. D. Hanssen, MD, Professor of Orthopaedics F. H. Sim, MD, Professor of Orthopaedics

Department of Orthopaedic Surgery

Mayo Graduate School of

Medicine, Mayo Clinic, 200 First street S. W., Rochester, Minnesota 55905, USA.

Correspondence should be sent to Dr G. C. Babis; e-mail: george.babis@gmail.com

(C)2010 British Editorial Society of Bone and Joint Surgery doi:10.1302/0301-620X.92B3. $23112 \$ 2.00$

J Bone Joint Surg [Br] 2010;92-B:349-55. Received 20 July 2009; Accepted after revision November 2009

We report the use of an allograft prosthetic composite for reconstruction of the skeletal defect in complex revision total hip replacement for severe proximal femoral bone loss. Between 1986 and 1999, 72 patients (20 men, 52 women) with a mean age of 59.9 years (38 to 78) underwent reconstruction using this technique.

At a mean follow-up of 12 years ( 8 to 20) 57 patients were alive, 14 had died and one was lost to follow-up. Further revision was performed in 19 hips at a mean of 44.5 months (11 to 153) post-operatively. Causes of failure were aseptic loosening in four, allograft resorption in three, allograft nonunion in two, allograft fracture in four, fracture of the stem in one, and deep infection in five. The survivorship of the allograft-prosthesis composite at ten years was $69.0 \%$ (95\% confidence interval 67.7 to 70.3$)$ with 26 patients remaining at risk. Survivorship was statistically significantly affected by the severity of the pre-operative bone loss (Paprosky type IV; $p=\mathbf{0 . 0 1 9}$ ), the number of previous hip revisions exceeding two $(p=0.047)$, and the length of the allograft used $(p=0.005)$.

Approximately 73 to 90 primary total hip replacements (THRs) per 100000 of the population are performed each year. ${ }^{1}$ As the indications for joint replacement expand, the number of revision THRs is anticipated to increase. ${ }^{1}$ Massive osteolysis, stress-shielding or multiple revisions can eventually lead to extensive loss of bone in the proximal femur ${ }^{2}$ making revision surgery with conventional techniques unfeasible.

In cases of massive bone loss a combination of the use of an allograft with the femoral component has allowed reconstruction of the proximal femur. ${ }^{3-5}$ While the results of this technique have been encouraging, there are a wide range of complications. ${ }^{6-10}$ We report the radiological and functional outcome of the use of an allograft-prosthesis composite. Our hypothesis was that specific factors such as the extent of the loss of femoral bone stock, the number of previous revisions, the length of the allograft, the type of allograft-host bone junction, the type of fixation of the allograft to the host bone and the use of strut grafts may affect the survivorship and the incidence of complications.

\section{Patients and Methods}

Between 1986 and 1999, 72 patients (20 men and 52 women; 72 hips) with a mean age of 59.9 years (38 to 78 ) underwent revision THR using an allograft-prosthesis composite to reconstruct the proximal femur. The inclusion criteria were at least one previous THR and AAOS type-III extensive circumferential bone loss of the proximal femur. ${ }^{11}$ According to the classification of Aribindi and Paprosky, ${ }^{12}$ 17 hips were type III-B and 55 type IV. The exclusion criteria were a history of periprosthetic infection or malignancy of the proximal femur. Patients included in the study had a mean of 2.6 (1 to 6 ) previous hip operations. The revision operations using an allograftprosthesis composite were performed mainly by three senior surgeons (MIO'C, ADH, FHS).

The allograft was stored in the hospital bone bank (accredited by the American Association of Tissue Banks ${ }^{13}$ ) at a temperature of $-70^{\circ} \mathrm{C} .{ }^{14}$ Pre-operatively, the radiographs were templated to obtain the approximate size of the bone defect and an appropriate allograft in length and diameter was ordered. Preoperative planning included options for both step-cut and telescoping procedures in case of allograft-host bone mismatch. The level of the osteotomy and the intended length of allograft to be used were also templated pre-operatively in order to avoid producing unacceptable leglength discrepancy. The mean length of the allografts was $13.1 \mathrm{~cm}$ (8 to 21).

A modified Hardinge approach ${ }^{15}$ was used in 44 hips, a posterior approach in 11 and a transtrochanteric approach in 17 . The proxi- 


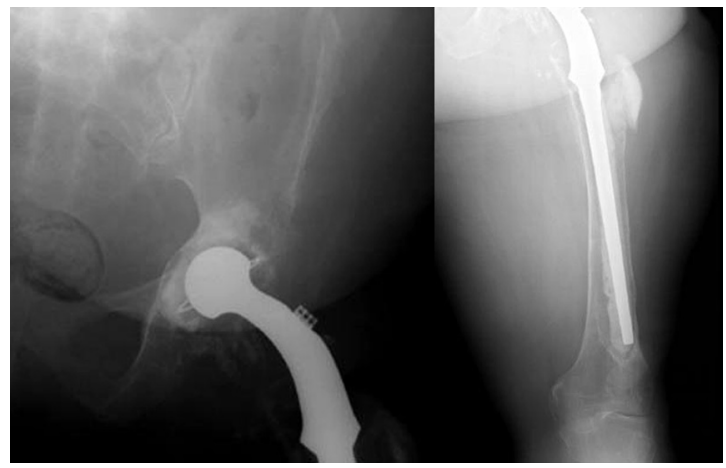

Fig. 1a

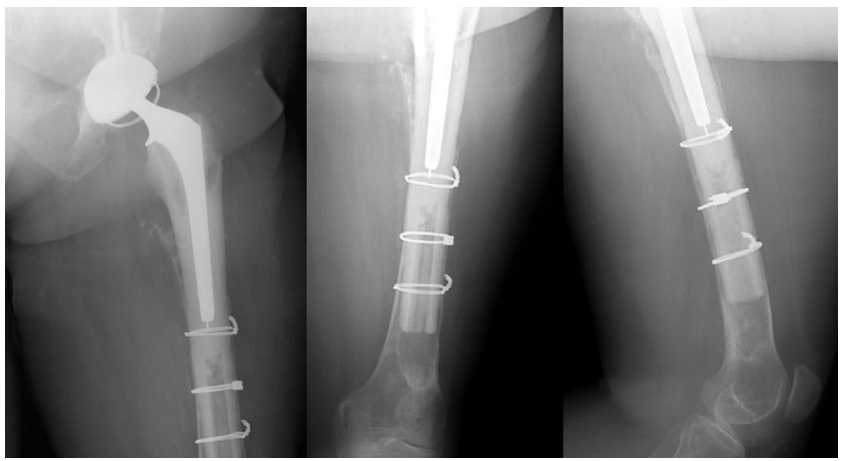

Fig. 1b

Radiographs of a failed hip reconstruction with a megaprosthesis and severe bone loss of the proximal femur a) pre-operatively and b) postoperative views showing the radiological appearance after the intussusception technique.

mal femur was carefully exposed and any remnants were preserved with their soft-tissue attachments to be used later as bone graft wrapped around the allograft. A step-cut osteotomy to enhance rotational stability at the allografthost bone junction was adopted in 62 hips. In 35 hips a short step cut of approximately $2 \mathrm{~cm}$ was created, whereas in 27 hips a long step, greater than $5 \mathrm{~cm}$ and extending to a maximum of $9 \mathrm{~cm}$ was used. In ten hips with a mismatch of the allograft-host bone dimensions, a telescoping procedure (intussusception technique) of the smaller diameter into the larger bone was selected (Fig. 1).

The implant was cemented into the allograft in all cases. When possible, distal fixation was achieved using cementless long stems (44 hips), bypassing the allograft-host junction by at least $4 \mathrm{~cm}$. In cases in which reaming of the allograft to allow distal cementless fixation would have resulted in a risk of fracture, a stem of smaller diameter was cemented into the host bone ( 22 hips). In six hips rotational stability could not be achieved with strut grafts and cerclage wires. The allograft host junction was therefore secured and fixed using plates and screws.

Autograft bone from the reamings of the distal femoral canal and all the available local host bone were applied to the allograft-host junction to encourage union. Rotational stability was reinforced by two or more allograft cortical struts and cables except for the six hips in which the allograft-host junction had been secured by plates and screws. The residual proximal part of the host femur was wrapped around the allograft and held by cables. An attempt was made to bring the viable residual proximal femoral bone distally to wrap around the junction of the osteotomy to encourage union.

Revision of the acetabular component was performed in 58 of the 72 hips. The pre-operative classification of Aribindi and Paprosky ${ }^{12}$ of the acetabular defects was type I in two, type II in 27 and type III in 29. According to the classification system of the American Academy of Orthopaedic Surgeons, ${ }^{16}$ seven were segmental, eight cavitary, and 43 combined. In 14 cases the acetabular component was not revised since both the pre-operative radiological evaluation and the intra-operative findings showed no evidence of loosening. When acetabular revision was required this was always undertaken first. In 39 hips a cementless hemispherical acetabular component was used, in five hips a cemented acetabular component and in 14 an antiprotrusion cage with a cemented acetabular component. The size of the femoral head used was $22 \mathrm{~mm}$ in eight hips, $28 \mathrm{~mm}$ in 54 and $32 \mathrm{~mm}$ in six. In four hips a $28 \mathrm{~mm}$ femoral head was used with a constrained acetabular insert.

Reconstruction of the abductor mechanism was a priority in all patients to prevent dislocation and limping. The greater trochanter was attached to the allograft by previously placed wires in 15 hips or by Dall-Milles cables in 13. In the remaining 44 hips repair of the abductors was done by suturing the remnant of the gluteus tendon attached to the allograft to the host tendon using non-absorbable sutures.

The clinical status of the patients was evaluated before the operation using a modified Harris hip score (HHS) ${ }^{17}$ without any range of movement assessments. Living patients either returned for clinical and radiological evaluation or were assessed by a local orthopaedic surgeon by radiography and measurement of the HHS. The radiographs and clinical notes of those who had died were reviewed, and relatives were contacted if necessary to assess the patient's functional status before death. All preoperative and post-operative radiological evaluations were carried out by one independent senior orthopaedic surgeon and one fellow (GCB, VIS) in adult reconstruction. An inter- and intra-observer agreement assessment was done for both pre- and post-operative radiological evaluations.

The radiographs were examined for evidence of trochanteric and allograft-host union, endosteal and periosteal resorption, loosening of the component, fracture of the cement and periprosthetic fracture. Union was defined as callus formation, periosteal sclerosis and lack of radiolucent line between allograft and host bone. The allograft was divided into zones as described by Gruen, McNeice and Amstutz. ${ }^{18}$ Zone 4 was excluded because of the allograft-host junction. The stability of the implant was assessed for the presence of radiolucent lines according to Gruen et $\mathrm{l}^{18}$ and migration of the implant. Definite loosen- 
Table I. Complications leading to revision of the allograft-prosthesis composite

\begin{tabular}{lccl}
\hline Complication & Number of hips & Complication rate (\%) & Type of operation \\
\hline Allograft nonunion & 2 & 2.8 & Revision with new allograft \\
Aseptic loosening & 4 & 5.6 & Revision with new allograft \\
Allograft resorption & 3 & 4.2 & Revision with new allograft \\
Allograft fracture & 4 & 5.6 & Revision with new allograft \\
Femoral stem fracture & 1 & 1.4 & Revision with new allograft \\
Deep infection & 5 & 6.9 & Two-stage revision/intravenous antibiotics \\
Total & 19 & 26.5 & \\
\hline
\end{tabular}

Table II. Early complications leading to re-operation without revision of the allograft-prosthesis composite

\begin{tabular}{|c|c|c|c|}
\hline Complication & Number of hips & Complication rate (\%) & Type of operation \\
\hline Dislocation & 8 & 11.1 & $\begin{array}{l}\text { Closed reduction ( } 5 \text { hips) } \\
\text { Recurrent dislocation placement of a larger } \\
\text { femoral head and re-attachment of the } \\
\text { abductors ( } 3 \text { hips) } \\
\text { Second operation for constrained liner ( } 1 \\
\text { hip) }\end{array}$ \\
\hline Haematoma & 6 & 8.3 & Wash-out \\
\hline Trochanteric bursitis & 4 & 5.6 & Irritation from wires and cables. Removed \\
\hline Trochanteric nonunion/trochanteric migration & 4 & 5.6 & Trochanteric re-attachment. Hip spica \\
\hline Supracondylar femoral fracture & 2 & 2.8 & Internal fixation \\
\hline Total & 24 & 33.4 & \\
\hline
\end{tabular}

ing was defined as migration of the implant of more than 3 $\mathrm{mm}$ or fracture of the cement. Mild allograft resorption was classified as partial-thickness resorption of less than 1 $\mathrm{cm}$ in length, moderate resorption as partial-thickness resorption of more than $1 \mathrm{~cm}$ in length and severe resorption as full-thickness resorption of any length. ${ }^{19}$

Statistical analysis. The Kaplan-Meier method was used for survival analysis, and the $95 \%$ confidence intervals (CI) were calculated. ${ }^{20}$ Factors studied for a potential relationship to survival included classification of the femoral defect, the number of revisions, step-cut or telescoping of the allograft, and cementless or cemented distal fixation. Pairwise comparisons for all factors observed were weighted with the log-rank (Mantel-Cox ${ }^{21}$ ) test of equality of survival distributions for the different levels of each factor which was examined. The level of statistical significance was set at a $p$-value $\leq 0.05$. Failure was defined as planned or actual removal of the original allograft-prosthesis construct or severe radiological resorption of the allograft. Patients who had died or had been lost to follow-up were censored as of their latest date of evaluation.

\section{Results}

At a mean follow-up of 12 years (8 to 20) after revision, 57 patients were alive, 14 had died, and one had been lost to follow-up.

Revision of the allograft-prosthesis composite had been performed in 19 hips at a mean of 44.5 months (11 to 153) post-operatively. The causes of revision was allograft nonunion in two hips, aseptic loosening in four, allograft resorption in three, allograft fracture in four and fracture of the femoral component in one. In five hips reconstruction was complicated by deep infection leading to early failure and staged revision (Table I).

Dislocation occurred in eight hips and was managed by closed reduction. In all of these a $22 \mathrm{~mm}$ femoral head had been used. Regarding the association of the dislocation with the abductor mechanism, in four hips failure of the trochanteric re-attachment was evident with trochanteric migration in two and trochanteric nonunion in two. In the other four dislocated hips a tendon-to-tendon repair had been performed. Three of these eight patients had a recurrent dislocation and underwent further surgery in which a larger $28 \mathrm{~mm}$ femoral head was used with exchanging of the polyethylene liner and re-attachment of the abductors. One of these underwent further revision to a constrained acetabular liner. Other complications requiring reoperation were haematoma and persistent drainage which required washing out in six hips and trochanteric bursitis and irritation from wires and cables which had to be removed in four. Trochanteric nonunion complicated by migration and deficiency of the abductors occurred in four hips. The latter was managed by trochanteric reattachment and protection of the hip in a spica for eight weeks. Two cases of supracondylar femoral fracture were managed by open reduction and internal fixation (Table II).

The survival rate of the allograft-prosthesis composite at ten years was $69.0 \%$ (95\% CI 67.7 to 70.3$)$ when 26 patients (hips) were at risk (Fig. 2). At five years the survival rate was $78.2 \%$ (95\% CI 77.2 to 79.2 ). The KaplanMeier survival rate at ten years when both components were revised was $84.8 \%$ (95\% CI 79.8 to 94.6 ).

We carried out assessment of the differences in survival time in relation to the types of femoral defect according to 


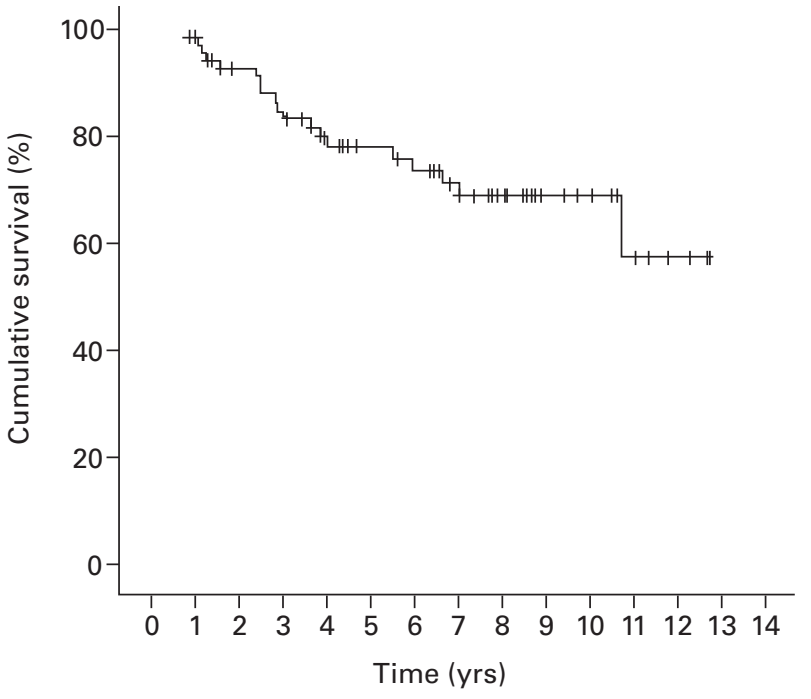

Fig. 2

Kaplan-Meier survival curve of the hips with allograft-prosthesis composite reconstructions.

the classification of Aribindi and Paprosky. ${ }^{12}$ The pairwise comparison using the log-rank test showed that survival was significantly worse for type IV than type III-B (logrank, $\mathrm{p}=0.019)$.

The survival was also affected by the length of the proximal femoral allograft used for reconstruction. Specifically, linear correlation of different lengths of the allograft-prosthesis composite with survival was estimated using the Pearsons correlation and showed that the survival time had a negative correlation with allograft length $(r=0.78, p=0.005)$.

The survival time was assessed according to the number of THRs before revision with an allograft-prosthesis composite. The patients who had six THRs were not compared since only three hips were involved. We found a significant difference in the survival rate between the group with only one THR compared with that with three (log-rank (MantelCox) test, $\mathrm{p}=0.047$ ), four (log-rank (Mantel-Cox) test, $\mathrm{p}=0.05$ ) and five (log-rank (Mantel-Cox) test, $\mathrm{p}=0.026$ ) whereas there was no significant difference in the survival rate between those with only one THR and those with two (log-rank (Mantel-Cox) test, $\mathrm{p}=0.078$ ).

Specific technical parameters were evaluated in order to reveal any potential factors affecting the survival of the allograft prosthesis composite including the type of osteotomy and standardisation of the allograft-host bone junction as well as distal fixation into the host bone. The use of the intussusception technique (Fig. 1) was compared with typical step-cut osteotomy, but no significant difference was found (log-rank (Mantel-Cox) test, $\mathrm{p}=0.493)$. Furthermore, distal fixation with cementless stems was compared with cemented fixation and again no significant difference was found (logrank (Mantel-Cox) test, $\mathrm{p}=0.519$ ).

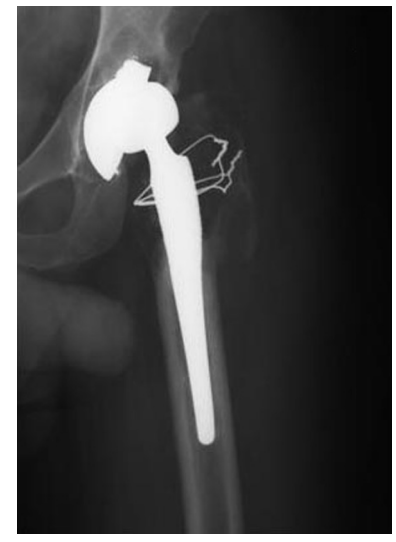

Fig. 3a

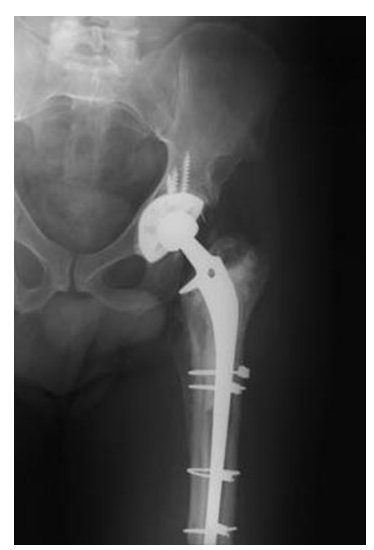

Fig. 3c

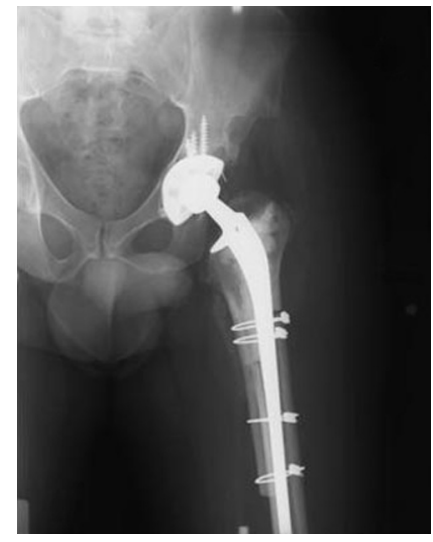

Fig. 3b
Radiographs of a 38-year-old man with reconstruction of a failed primary total hip replacement showing a) Pre-operative anteroposterior (AP) view of the left hip with extensive peritrochanteric radiolucency seven years after the initial replacement, b) a post-operative AP view with the allograft cemented proximally and a step-cut osteotomy and c) an AP view at 12 years after revision with union of the allograft-host junction.

Clinically, the HHS improved at follow-up at two years from a mean of 32 points (10 to 48 ) pre-operatively to a mean of 73 points ( 52 to 85 ), with 57 patients $(79.2 \%$ ) having an increase of more than 20 points. Pain was reported to be absent in 35 patients $(48.6 \%)$, slight or occasional in ten $(13.8 \%)$, mild in $13(18 \%)$, moderate in nine $(12.5 \%)$, marked in three $(4.1 \%)$, and totally disabling in two $(3 \%)$. At least one walking stick was required in 56 patients $(77.8 \%)$. At follow-up at five years, 63 patients $(87.5 \%)$ had an improvement of more than 20 points in the HHS compared with the pre-operative evaluation, reflecting both the efficacy of the reconstruction as well as the debilitated status of these patients before surgery. No relationship was noted between the improvement in the HHS score and the age of the patient $(\mathrm{p}=0.136)$ or the degree of pre-operative bone loss $(\mathrm{p}$ $=0.088$ ) using the Tukeys test for pairwise comparisons.

Radiological evaluation by the two independent observers (GCB, VIS) showed good interobserver (kappa = 0.77) and intra-observer agreement (kappa $=0.92)$. Union at the allograft-host junction was achieved in 59 of the 72 allografts after surgery (Fig. 3). In seven hips radiological union was evident by six months, in 31 by 12 and in 21 by 24 . In all hips protected weight-bearing throughout the whole process of allograft-host union was recom- 
Table III. Studies reporting the number of cases, the grade of allograft resorption and the survivorship of the allograft-prosthesis composites

\begin{tabular}{|c|c|c|c|c|}
\hline Author & Number of hips & Follow-up (yrs) & Allograft resorption & $\begin{array}{l}\text { Survivorship of the allograft- } \\
\text { prosthesis composite }\end{array}$ \\
\hline Gross and Hutchison $^{14}$ & 168 & 11 & 6 mild, 1 severe & $77 \%$ at 11 years \\
\hline Haddad et $\mathrm{al}^{24}$ & 40 & 8.8 & 9 mild, 4 moderate, 7 severe & $65 \%$ at 10 years \\
\hline Backley et $\mathrm{al}^{2}$ & 48 & 11 & 12 mild, 1 severe & $86 \%$ at 10 years \\
\hline Safir et $\mathrm{al}^{27}$ & 93 & 16.2 & 29 mild, 1 severe & $84 \%$ at 15 years \\
\hline Head et $a l^{8}$ & 22 & 28 & 5 mild & $73 \%$ at 2 years \\
\hline Haddad et $\mathrm{al}^{24}$ & 55 & 8.8 & 7 severe & $89 \%$ at 8 years \\
\hline Wang and Wang ${ }^{25}$ & 15 & 7.6 & 3 severe & $67 \%$ at 7 years \\
\hline
\end{tabular}

mended. In 13 hips union was not achieved, including the five complicated by infection, four of which subsequently underwent conversion to an excision arthroplasty and one to a two-stage re-revision. The remaining eight hips with aseptic nonunion were managed by re-revision of the allograft-prosthesis composite. Bone grafting to the allograft-host bone junction was not considered, since the nonunion was accompanied by an excessive resorption of the allograft.

Resorption of the allograft was classified as mild or moderate in nine hips $(12.5 \%)$. It was consistently identified on the periosteal surface in Gruen zones 1 in 3, 2 in 1, 5 in 1, 6 in 1 and 7 in 3 hips.

Trochanteric nonunion appeared in six of 28 hips $(21.4 \%)$ with trochanteric re-attachment by cables or wires. In two of these the greater trochanter had become detached from its fixation.

\section{Discussion}

The problem of femoral bone loss after failure of THR is expected to increase with the large number of revision procedures performed. Identifying a successful surgical treatment is critical to the care of these patients.

Proximal femoral allografts have been used in revision THR for many years., ${ }^{22-24}$ Allograft offers mechanical properties similar to those of the patient's bone and allows reconstruction of sizeable deficits. ${ }^{23,24}$ In addition, it allows re-attachment of the hip abductors in an effort to preserve the function of the hip and gait. ${ }^{24,25}$

The indications for the use of a structural allograft are not absolutely established. Gross and Hutchison ${ }^{14}$ support the use of proximal femoral allograft for the reconstruction of circumferential defects of more than $3 \mathrm{~cm}$ in length from the calcar, some combined defects and in some cases of femoral discontinuity. These conditions are likely to occur after failure of a tumour prosthesis or calcar replacement implants with subsidence or in a femur which is too deficient or expanded for impaction bone grafting. In our study we set, as inclusion criteria, femoral bone loss classified as type III according to the $\mathrm{AAOS}^{11}$ or type III-B or greater according to the classification of Aribindi and Paprosky. ${ }^{12}$

Matching the size of the allograft to the host bone may be a problem and has been addressed by the use of cortical struts or step-cuts and intussusception of the allograft bone into the host. ${ }^{2,8,26,27}$ When rigidly fixed, strut grafts also provide an extensive surface area of contact with the host bone for supplementary union and incorporation. ${ }^{27}$ However, in our series, step-cut osteotomy and the intussusception technique were found to be comparable in terms of survivorship of reconstruction. Further analysis regarding the size of the different step-cut techniques and the achievement of rotational stability could not be performed because of the lack of statistical power due to the small sample size of each group.

Although the technique of cementing of the stem into the proximal femoral allograft has been well documented, ${ }^{14,23}$ there is no consensus regarding distal fixation. Our results showed that there was no statistically significantly difference between cemented and cementless distal fixation regarding survivorship. Elsewhere, it has been stated that distal cementing should be avoided since it may compromise the union of the allograft-host junction and the distal femur for future procedures. ${ }^{14}$

The survivorship of an allograft-prosthesis composite reconstruction has been reported to range from $65 \%$ to $86 \%$ at ten years. ${ }^{2,8,10,23-25,27}$ (Table III). These results are comparable with those of our series with survival rates at two years of $92.7 \%$, at five years of $78.2 \%$, and at ten years of $69 \%$ (Fig. 2). The interpretation of many clinical studies is, however, a problem because of the lack of uniformity in the classification of the loss of bone stock and the number of revisions before reconstruction by an allograft-prosthesis composite.

In our series, statistically significant differences were seen in the outcome based on the number of revisions before reconstruction with an allograft-prosthesis composite. Additionally, a statistically significant difference was found between the Paprosky types III-B and IV femoral bone loss. These findings are not unexpected. Patients with a history of numerous revisions are more likely to present with more marked bone loss, making the outcome of rerevision less predictable.

The literature documents a variety of complications and their rates in reconstruction with an allograft-prosthesis composite. Hip dislocation, nonunion at the allograft-host bone junction, post-operative infection, periprosthetic fracture and aseptic loosening of the femoral component are the most frequently recorded. ${ }^{2,6,8,14,23}$ The rate of disloca- 
tion ranges from $3.1 \%$ to $54 \%$, of nonunion of the allograft host bone junction from $4.7 \%$ to $20 \%$, of trochanteric nonunion from $25 \%$ to $27 \%$, of post-operative infection from $3.3 \%$ to $8 \%$, of periprosthetic fracture from $2 \%$ to $5 \%$ and of aseptic loosening from $1 \%$ to $12 \%$. The rate of these complications in our study is comparable. We encountered deep infection in five hips $(6.9 \%)$ which was also similar to that of other studies. ${ }^{2,14,22,23,25,27-30}$ Large segmental allografts pose a higher risk for infection. ${ }^{31}$

Union at the allograft-host junction is a significant factor predisposing to the success of the construct. This was achieved in 59 of the 72 allografts in our series and nine hips $(12.5 \%)$ had moderate or mild allograft resorption, which in three was located at the greater trochanteric area (Gruen zone 1). Resorption was always seen on the periosteal surface of the allograft which would be expected since cement on the endosteal surface inhibits access by host granulation tissue and the dead allograft is not a source of viable cells. ${ }^{30,31}$ On the periosteal surface, however, there is access to host tissue and vascularisation which could lead to resorption.

Other authors have described varying degrees of graft resorption similar to our findings. ${ }^{9,14,23,27}$ At follow-up at 11 years Blackley et $\mathrm{al}^{2}$ reported 12 cases of mild to moderate and only one of severe resorption in 48 allograftprosthesis composites in which the residual host proximal femur had been wrapped around the allograft.

The functional outcome of our patients also reflects the experience of other series. ${ }^{2,23}$ Proximal femoral replacement prostheses are an alternative option in cases of severe loss of proximal femoral bone. ${ }^{32-34}$ Initially these devices were intended for use after tumour resection, but their role has been extended to the management of proximal femoral deficiency in hip revision surgery. We reserve their use in revision surgery to older, less active patients. In one series the femoral replacement component had a survival of $81 \%$ at 11 years with revision as the endpoint. ${ }^{33}$

Stability of the hip after reconstruction with an allograftprosthesis composite or proximal femoral replacement can be compromised with dislocation due to deficiency of the abductor mechanism or an inability to secure the abductor mechanism to the revision construct. ${ }^{35}$ Options for attachment of the abductor mechanism, both to the implant or to the tensor fascia lata, are limited, and probably influence the risk of dislocation. However, this extensive surgery with this associated problem of abductor re-attachment may be the only solution if a resection arthroplasty is to be avoided. ${ }^{33,34,36}$

Our study has several limitations. It is based on a retrospective analysis of clinical and radiological data. A wide range of prostheses, including cemented and cementless implants, and a variety of allograft lengths were used with no uniformity in the type of implant or the method of fixation either within the allograft or the host.

The strengths of our study include the relatively large number of patients who were followed up for a sufficient period. It is also the only study to compare the clinical and radiological outcome, as well as the overall survivorship on the basis of several technical parameters, such as bone stock, the number of revisions and different methods of fixation.

In conclusion, reconstruction of massive proximal femoral bone loss using an allograft-implant composite can give satisfactory results, but the number of previous hip replacements and the severity of proximal femoral bone loss were associated with a worse outcome.

No benefits in any form have been received or will be received from a commercial party related directly or indirectly to the subject of this article.

\section{References}

1. Lohmander LS, Engesaeter LB, Herberts $\mathbf{P}$, et al. Standardized incidence rates of total hip replacement for primary hip osteoarthritis in the 5 Nordic countries: similarities and differences. Acta Orthop 2006;77:733-40.

2. Blackley HRL, Davis AM, Hutchison CR, et al. Proximal femoral allografts for reconstruction of bone stock in revision arthroplasty of the hip. J Bone Joint Surg [Am] 2001;83-A:346-54.

3. Haddad FS, Garbuz DS, Masri BA, et al. Femoral bone loss in patients managed with revision hip replacement: results of circumferential allograft replacement. $J$ Bone Joint Surg [Am] 1999;81-A:420-36.

4. Musculo DL, Petracchi LJ, Ayerza MA, Calabrese ME. Massive femoral allografts followed for 22 to 36 years: report of six cases. J Bone Joint Surg [Br] 1992:74-B:887-92.

5. Shin DS, Weber KL, Chao EY, An KN, Sim FH. Reoperation for failed prosthetic replacement used for limb salvage. Clin Orthop 1999;358:58-63.

6. Chandler H, Clark J, Murphy S, et al. Reconstruction of major segmental loss of the proximal femur in revision total hip arthroplasty. Clin Orthop 1994;298:67-74.

7. Roberson JR. Proximal femoral bone loss after total hip arthroplasty. Orthop Clin North Am 1992;23:291-302.

8. Head WC, Berklacich FM, Malinin TI, Emerson RH Jr. Proximal femoral allografts in revision total hip arthroplasty. Clin Orthop 1987;225:22-36.

9. Masri BA, SpangehI MJ, Duncan CP, Beauchamp CP, Myerthal SL. Proximal femoral allografts in revision total hip arthroplasty: a critical review. J Bone Joint Surg [Br] 1995;77-B (Suppl III):306-7.

10. Zmolek JC, Dorr LD. Revision total hip arthroplasty: the use of solid allograft. $J$ Arthroplasty 1993:8:361-70.

11. D'Antonio J, McCarthy JC, Bargar WL, et al. Classification of femoral abnormalities in total hip arthroplasty. Clin Orthop 1993;296:133-9.

12. Aribindi R, Paprosky WG. Bypass fixation. Orthop Clin North Am 1998;29:319-29

13. Fawcett K, Barr AR. Tissue banking. Arlington, Virginia: American Association of Blood Banks, 1987:67-96.

14. Gross AE, Hutchison CR. Proximal femoral allografts for reconstruction of bone stock in revision hip arthroplasty. Orthopedics 1998;21:999-1001.

15. Hardinge K. The direct lateral approach to the hip. J Bone Joint Surg [Br] 1982;64B:17-19.

16. D'Antonio JA, Capello WN, Borden LS, et al. Classification and management of acetabular abnormalities in total hip arthroplasty. Clin Orthop 1989;243:126-37.

17. Harris WH. Traumatic arthritis of the hip after dislocation and acetabular fractures: treatment by mold arthroplasty: an end-result study using a new method of result evaluation. J Bone Joint Surg [Am] 1969;51-A:737-55.

18. Gruen TA, McNeice GM, Amstutz HC. "Modes of failure" of cemented stem type femoral components: a radiographic analysis of loosening. Clin Orthop 1979;141:1727.

19. Gross AE, Hutchison CR, Alexeeff M, et al. Proximal femoral allografts for reconstruction of bone stock in revision arthroplasty of the hip. Clin Orthop 1995;319:151-8.

20. Kaplan EL, Meier P. Nonparametric estimation from incomplete observations. J Am Stat Assoc 1958;53:457-81.

21. Mantel N. Evaluation of survival data and two new rank order statistics arising in its consideration. Cancer Chemother Rep 1966;50:163-70.

22. Graham NM, Stockley I. The use of structural proximal femoral allografts in complex revision hip arthroplasty. J Bone Joint Surg [Br] 2004;86-B:337-43.

23. Haddad FS, Garbuz DS, Masri BA, Duncan CP. Structural proximal femoral allografts for failed total hip replacements: a minimum review of five years. J Bone Joint Surg [Br] 2000;82-B:830-6. 
24. Haddad FS, SpangehI MJ, Masri BA, Garbuz DS, Duncan CP. Circumferentia allograft replacement of the proximal femur: a critical analysis. Clin Orthop 2000;371:98-107.

25. Wang JW, Wang CJ. Proximal femoral allografts for bone deficiencies in revision hip arthroplasty: a medium-term follow-up study. J Arthroplasty 2004;19:845-52.

26. Vastel L, Lemoine CT, Kerboull M, Courpied JP. Structural allograft and cemented long-stem prosthesis for complex revision hip arthroplasty: use of a trochanteric claw plate improves final hip function. Int Orthop 2007;31:851-7.

27. Safir O, Kellet CF, Flint M, Backstein D, Gross A. Revision of the deficient proximal femur with a proximal femoral allograft. Clin Orthop 2009;467:206-12.

28. Fox EJ, Hau MA, Gebhardt MC, et al. Long-term follow-up of proximal femora allografts. Clin Orthop 2002;397:106-13.

29. Kellett CF, Boscainos PJ, Maury A, et al. Proximal femoral allograft treatment of Vancouver type-B3 periprosthetic femoral fractures after total hip arthroplasty: surgical technique. J Bone Joint Surg [Am] 2007;89-A(Suppl 2, Pt 1):68-79.
30. Enneking WF, Mindell ER. Observations on massive retrieved human allografts. $J$ Bone Joint Surg [Am] 1991;73-A:1123-42.

31. Kandel RA, Pitzker KPH, Langer F, Gross A. The pathological features of massive osseous grafts. Hum Pathol 1984;15:141-6

32. Parvizi J, Tarity TD, Slenker N, et al. Proximal femoral replacement in patients with non-neoplastic conditions. J Bone Joint Surg [Am] 2007;89-A:1036-43.

33. Malkani AL, Sim FH, Chao EYS. Custom-made segmental femoral replacement prosthesis in revision total hip arthroplasty. Orthop Clin North Am 1993;24:727-33.

34. Malkani AL, Settecerri JJ, Sim FH, Chao EY, Wallrichs SL. Long-term results of proximal femoral replacement for non-neoplastic disorders. J Bone Joint Surg $[\mathrm{Br}]$ 1995;77-B:351-6.

35. Crawford SA, Siney PD, Wroblewski BM. Revision of failed total hip arthroplasty with a proximal femoral modular cemented stem. J Bone Joint Surg [Br]2000;82-B:684-8.

36. Haentjens P, DeBoeck H, Opdecam P. Proximal femoral replacement prosthesis for salvage of failed hip arthroplasty: complications in a 2-11 year follow-up study in 19 elderly patients. Acta Orthop Scand 1996;67:37-42. 